\section{Kidney \\ Blood Pressure Research}

Kidney Blood Press Res 2012;36:139-148

\begin{tabular}{l|l}
\hline DOI: $10.1159 / 000341490$ & (c 2012 S. Karger AG, Basel \\
\hline
\end{tabular}

www.karger.com/kbr

139

Original Paper

\title{
Prevalence of and Factors Associated with Chronic Kidney Disease (CKD) in Japanese Subjects without Notable Chronic Diseases, Undergoing an Annual Health Checkup
}

\author{
Yoshiteru Ohno $^{\mathrm{a}, \mathrm{b}}$ Eiji Ishimura ${ }^{\mathrm{b}}$ Toshihide Naganumac Kyoko Kondo ${ }^{\mathrm{d}}$ \\ Wakaba Fukushima ${ }^{\mathrm{e}}$ Kayo Muif ${ }^{f}$ Masaaki Inaba ${ }^{a}$ Yoshio Hirota ${ }^{\mathrm{C}}$
}

\begin{abstract}
aDepartment of Metabolism, Endocrinology and Molecular Medicine, Osaka City University Graduate School of Medicine, Osaka, Japan, 'Department of Nephrology, Osaka City University Graduate School of Medicine, Osaka, Japan, 'Department of Urology, Osaka City University Graduate School of Medicine, Osaka, Japan, 'Osaka City University Graduate School of Medicine, Osaka, Japan, ${ }^{\mathrm{d}}$ Department of Public

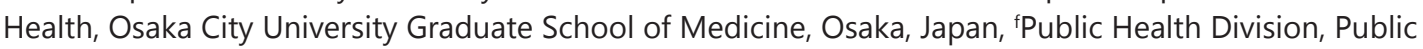
Health Bureau, Osaka city, Japan
\end{abstract}

\section{Key Words}

Chronic kidney disease $\bullet$ Subjects without notable chronic disease $\bullet$ Health checkup $•$ Metabolic abnormalities

\begin{abstract}
Background: The prevalence of chronic kidney disease (CKD) is increasing dramatically. The aim of the present study is to explore the prevalence of and the factors associated with CKD in subjects without notable chronic disease. Methods: In a cross-sectional study, we analyzed the annual health checkup data of 39,211 residents (11,636 males and 27,575 females) aged $40-74$ years $(58.6 \pm 8.6$ years) without notable chronic diseases, who underwent a health checkup at the Public Health Centers of Osaka city. CKD was defined as those with an estimated glomerular filtration rate (eGFR) less than $60 \mathrm{ml} / \mathrm{min} / 1.73 \mathrm{~m}^{2}$ and/or urinary protein of (+) or more. Results: The overall prevalence of CKD was $20.5 \%$, and increased remarkably with age. Multivariate logistic regression analysis demonstrated that male gender (OR: 0.83, $p<0.0001)$, age of $50-59$ years $(2.92, p<0.0001)$, age of $60-74$ years $(4.92, p<0.0001)$, the presence of diabetes $(0.80, p=0.0307)$, dyslipidemia $(1.21, p=0.0138)$, obesity $(1.23, p<0.0001)$, hyperuricemia $(2.63, p<0.0001)$ and a history of cardiovascular disease $(1.26, p=0.0135)$ were significant factors that were independently associated with CKD. Conclusions: In urban subjects without notable chronic disease, the prevalence of CKD was $20.5 \%$. Several metabolic abnormalities, i.e., dyslipidemia and hyperuricemia, were significantly associated with CKD.
\end{abstract}




\section{Kidney \\ Blood Pressure Research}

Kidney Blood Press Res 2012;36:139-148

\begin{tabular}{l|l}
\hline DOI: $10.1159 / 000341490$ & (c) 2012 S. Karger AG, Basel
\end{tabular}

Published online: October 25, 2012

www.karger.com/kbr

140

\section{Introduction}

Chronic kidney disease (CKD) is a worldwide problem, and its prevalence is increasing dramatically [1]. According to data from the National Health and Nutrition Examination Surveys (NHANES), the prevalence of CKD in the United States was 13.1\% between 1999 and 2004, which was increased compared with the prevalence of $10.0 \%$ noted during the 1994-1998 period [1].

The number of chronic dialysis patients has been increasing over the last three decades in Japan, and reached 297,126 in 2010. The prevalence of GFR less than $60 \mathrm{~mL} / \mathrm{min} / 1.73 \mathrm{~m}^{2}$ has been reported to be as high as $19.1 \%$ in the adult Japanese population [2]. Furthermore, it has been established that in addition to being a risk factor for progressive kidney failure, CKD is also a risk factor for cardiovascular morbidity and mortality [3-5]. Considering these points, understanding the prevalence of CKD, increasing disease awareness and the identification of factors associated with CKD at the early stage are important, critical and could be beneficial in reducing the risk of end stage renal disease (ESRD) and cardiovascular mortality. It is also important to determine cost-effective strategies for the prevention of ESRD.

Osaka City is one of the most affluent cities in Japan, with a total population of about 2.6 million. In Osaka City, the municipal government policy advises all adult residents to undergo a health status checkup every year, either at their local medical doctors or at the Public Health Centers of the 24 districts. In this political strategy, residents, who do not regularly visit a local medical doctor, undergo an annual health checkup in the Public Health Centers. In the present study, we analyzed the health checkup data of residents who visited the Public Health Centers; i.e., residents without notable chronic diseases. Since several previous studies have examined subjects including those with known chronic disease with treatment, such as hypertension, dyslipidemia and diabetes [1, 2, 6-9], we focused on the prevalence of CKD and factors associated with CKD in subjects without known chronic disease or any medication, i.e. healthy population, using a cross-sectional design. Furthermore, we aimed to determine how and to what extent unaware diseases that have been defined by several Japanese guidelines, such as hypertension [10], diabetes [11], dyslipidemia [12], obesity [13], and hyperuricemia [14] could really affect the presence of CKD. Our study aimed to allow us to identify the appropriate interventional strategies that could contribute to the effective and efficient management of both the health costs and quality of life for latent and potential subjects with CKD.

\section{Materials and Methods}

\section{Study population}

This study was cross-sectional in design. A total of 63,704 residents $\geq 40$ years of age underwent their annual health checkup at the Public Health Centers located in each of the 24 wards of Osaka city between April 2001 and March 2002. According to our policy of health promotion, which is particularly focused on working people of middle to early old age, we selected the data of 40 - to 74-year-old subjects $(n=52,825)$. In order to examine the residents without notable chronic disease, those who were treated at any hospital or by any local medical doctor were excluded $(n=12,622)$. After further exclusion of those with missing data for the current analysis ( $n=992)$, a total of 39,211 individuals (males: 11,636, females: 27,575) were examined in the study. None of the subjects were undergoing treatment with any medications, based on information provided during a self-administered questionnaire at the health checkup. None of the subjects had previously diagnosed kidney diseases or chronic renal insufficiency, based upon the self-administered questionnaire. All subjects attended their respective Health Center by themselves, with no symptoms related to possible kidney diseases, i.e., decrease in urine and edema, suggesting there were very little possibility of acute renal failure. 


\section{Kidney \\ Blood Pressure Research}

Kidney Blood Press Res 2012;36:139-148

\begin{tabular}{l|l}
\hline DOI: $10.1159 / 000341490$ & C 2012 S. Karger AG, Basel
\end{tabular}

Published online: October 25, 2012

www.karger.com/kbr
Screening protocol

In the annual health checkup program, body weight and height were measured for each participant. All participants were asked to complete self-administered questionnaires including information on their past history of cardiovascular diseases (CVD), i.e., myocardial infarction, angina pectoris, stroke and other CVD. Blood pressure was measured in a sitting position after an adequate resting period. Urinary analysis was performed by dip-stick test. Urinary protein levels were measured as $(-),( \pm),(+)$ and $(++)$. Blood was collected to measure blood glucose, total protein, serum total cholesterol, high density lipoprotein (HDL)-cholesterol, triglyceride, aspartate aminotransferase, alanine aminotransferase, $\gamma$-glutamyl transpeptidase, uric acid, creatinine, and urea. Serum creatinine was measured by an enzymatic method.
Table 1

\begin{tabular}{|c|c|}
\hline subjects & $\begin{array}{l}\text { Demographic } \\
\text { characteristics }\end{array}$ \\
\hline age (years) & $\begin{array}{l}58.6 \pm 8.6 / \text { median: } \\
60.0 \text { (range 40-74) }\end{array}$ \\
\hline $\begin{array}{l}\text { male / female } \\
\text { blood pressure (mmHg) }\end{array}$ & $11636 / 27575$ \\
\hline systolic & $126 \pm 18$ \\
\hline diastolic & $76 \pm 11$ \\
\hline hypertension (yes / no) & 8955 / 30216 \\
\hline diabetes (yes / no) & $693 / 38518$ \\
\hline serum creatinine $(\mathrm{mg} / \mathrm{dl})$ & $0.73 \pm 0.16$ \\
\hline eGFR (ml/min) & $71.5 \pm 13.4$ \\
\hline HDL-cholesterol (mg/dl) & $66 \pm 18$ \\
\hline nonHDL-cholesterol (mg/dl) & $160 \pm 38$ \\
\hline dyslipidemia (yes/no) & $917 / 38294$ \\
\hline body mass index & $22.8 \pm 3.0$ \\
\hline obesity (yes / no) & 8305 / 30906 \\
\hline uric acid (mg/dl) & $5.0 \pm 1.3$ \\
\hline hyperuricemia (yes / no) & 3316 / 35895 \\
\hline history of CVD (yes /no) & $634 / 38577$ \\
\hline
\end{tabular}

\section{Evaluation criteria}

Hypertension was defined as systolic pressure $\geq 140 \mathrm{mmHg}$ or diastolic pressure $\geq 90 \mathrm{mmHg}$, according to the guidelines of the Japanese Society of Hypertension [10]. Body mass index (BMI) was calculated using the following formula: BMI $\left[\mathrm{kg} / \mathrm{m}^{2}\right]=($ body weight $[\mathrm{kg}]) /(\text { height }[\mathrm{m}])^{2}$.

Obesity was defined as a body mass index $\geq 25$ according to Japanese Society for the Study of Obesity [13]. Diabetes was defined as serum fasting glucose $\geq 126 \mathrm{mg} / \mathrm{dl}$ or postprandial glucose $\geq 200 \mathrm{mg} / \mathrm{dl}$ [11, 15]. Fasting glucose was measured after overnight fast, and postprandial glucose was measured in the otherwise condition [11]. Dyslipidemia was defined as non-HDL cholesterol $>170 \mathrm{mg} / \mathrm{dl}$ or HDL cholesterol $\leq 40 \mathrm{mg} / \mathrm{dl}$ [12]. Hyperuricema was defined as serum uric acid $\geq 7.0 \mathrm{mg} / \mathrm{dl}$, according to the guidelines of the Japanese Society of Gout and Nucleic Acid Metabolism [14]. The estimated glomerular filtration rate (eGFR) was calculated using the following formula: eGFR $\left[\mathrm{ml} / \mathrm{min} / 1.73 \mathrm{~m}^{2}\right]=194 \times(\text { serum creatinine })^{-1.084} \times(\text { age })^{-0.287}$

The value was multiplied by a correction factor of 0.739 for women. This formula represents the eGFR for Japanese reported by the Japanese Society of Nephrology [16]. The presence of CKD was defined as the presence of either of the following, according to definition of KDIGO [17]; 1) eGFR<60 ml/min/1.73 ${ }^{2} ; 2$ ) urinary protein of $(+)$ or $(++)$.

Since our dipstick evaluation of urinary protein was very sensitive, and many participants exhibited $( \pm)$ levels of urinary protein, we included subjects with urinary protein of $(+)$ and $(++)$ as a component of CKD.

\section{Statistical analysis}

Data were expressed as the mean (standard deviation (SD)) or median (range), where appropriate. Multiple logistic regression analysis was performed to estimate the odds ratios (ORs) and confidence intervals (CIs) of factors potentially related to the presence of CKD. Gender, age (40-49 / 50-59 / 60-74 years) and the presence or absence of hypertension, diabetes mellitus, dyslipidemia, obesity, hyperuricemia, or a history of CVD were included in the model as explanatory variables. P-values $<0.05$ were considered statistically significant. These calculations were all conducted using SAS Version 9.1 (SAS Institute Inc., Cary, NC, USA).

\section{Results}

Demographic characteristics of the subjects

All 39,211 subjects (11,636 males and 27,575 females) with complete data entry were entered in the analysis. The mean age was $58.6 \pm 8.6$ years, and the median age was 60.0 


\section{Kidney Blood Pressure Research}

Kidney Blood Press Res 2012;36:139-148

\begin{tabular}{l|l}
\hline DOI: $10.1159 / 000341490$ & C 2012 S. Karger AG, Basel
\end{tabular}

Published online: October 25, 2012

www.karger.com/kbr

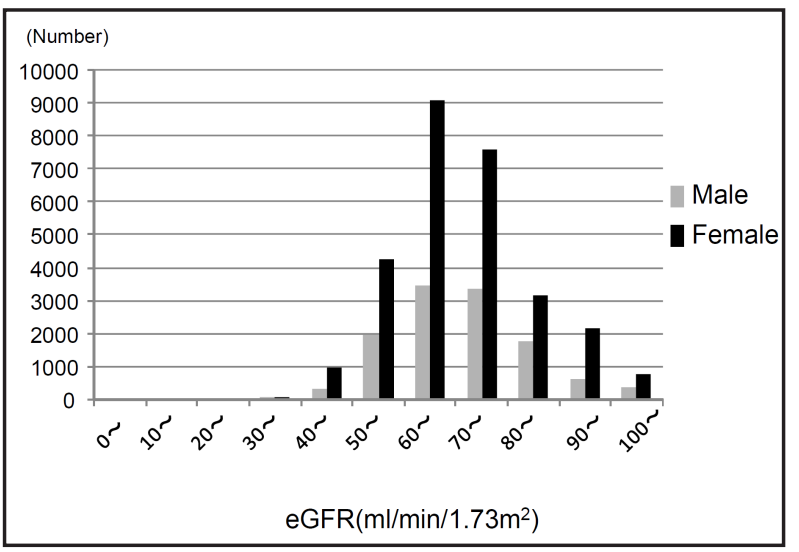

Fig. 1. Distribution of eGFR in the study participants according to gender. eGFR was distributed normally.

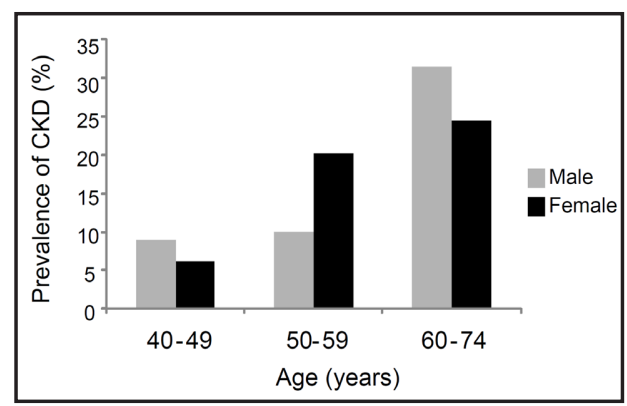

Fig. 2. Prevalence of $\mathrm{CKD}$ according to gender. Prevalence increased directly with age in both genders.

years (range 40-74 years). Table 1 shows the demographic characteristics of the subjects. Among the 39,211 participants, $22.8 \%$ had hypertension, $1.8 \%$ diabetes, $2.3 \%$ dyslipidemia, $21.2 \%$ obesity, $8.5 \%$ hyperuricemia, and $1.6 \%$ had a history of CVD.

The mean eGFRs $( \pm$ SD) in the age groups of 40-49, 50-59, and 60-74 years were 78.2 $( \pm 13.6), 73.3( \pm 13.0)$, and $68.0( \pm 12.5) \mathrm{mL} / \mathrm{min} / 1.73 \mathrm{~m}^{2}$, respectively. eGFR distribution is presented according to gender in Figure 1.

\section{Prevalence of CKD}

The overall prevalence of CKD was $20.5 \%$. The prevalence of CKD was $21.7 \%$ and 20.0 $\%$ in males and females, respectively. Figure 2 presents the prevalence of CKD according to each age group. The prevalence of CKD increased remarkably with age; the prevalence of CKD in the subjects aged 60 to 74 years $(31.4 \%$ in males and $24.5 \%$ in females) was much higher than the prevalence in the subjects that were 40 to 49 years of age $(9.0 \%$ in males and $6.2 \%$ in females).

Factors associated with the prevalence of CKD in all participants

Univariate logistic regression analysis demonstrated that the following factors were associated with the presence of CKD: (1) age of 50-59 years (OR: 2.85, 95\% CI: 2.56-3.16, $\mathrm{p}<0.0001)$, age of 60-74 years $(4.83,4.37-5.34, \mathrm{p}<0.0001)$; (2) male $(1.12,1.06-1.18$, $\mathrm{p}<0.0001)$; (3) hypertension $(1.23,1.16-1.30, \mathrm{p}<0.0001)$; (4) diabetes $(0.84,0.69-1.03$, $\mathrm{p}=0.0898) ;(5)$ dyslipidemia $(1.43,1.23-1.66, \mathrm{p}<0.0001) ;(6)$ obesity $(1.34,1.26-1.42$, $\mathrm{p}<0.0001)$; (7) hyperuricemia $(2.39,2.22-2.58, \mathrm{p}<0.0001)$; and (8) a history of CVD (1.43, 1.20-1.71, $\mathrm{p}<0.0001$ ) (Table 2).

Multivariate logistic regression analysis was performed including the following as explanatory variables: age, gender, presence of hypertension, diabetes, dyslipidemia, hyperuricemia, obesity, and a history of CVD. It demonstrated that the following factors were significantly associated with the presence of CKD: (1) age of 50-59 years (OR: 2.92, $95 \%$ CI: 2.63-3.25, p<0.0001), age of 60-74 years (4.92, 4.45-5.44, $\mathrm{p}<0.0001)$; (2) male (0.83, 0.78-0.88, $\mathrm{p}<0.0001)$; (3) diabetes $(0.80,0.66-0.98, \mathrm{p}=0.0307)$; (4) dyslipidemia $(1.21,1.04$ $1.42, \mathrm{p}=0.0138)$; (5) obesity $(1.23,1.16-1.31, \mathrm{p}<0.0001)$; (6) hyperuricemia $(2.63,2.41-2.86$, $\mathrm{p}<0.0001)$; and (7) a history of CVD $(1.26,1.05-1.51, \mathrm{p}=0.0135)$ (Table 2).

Factors associated with the prevalence of CKD in male and female participants

The univariate logistic regression analysis in males demonstrated that the following were significant factors associated with the presence of CKD: (1) age of 60-74 years (OR: 4.64, 


\section{Kidney \\ Blood Pressure Research}

Kidney Blood Press Res 2012;36:139-148

\begin{tabular}{l|l}
\hline DOI: $10.1159 / 000341490$ & (C) 2012 S. Karger AG, Basel
\end{tabular}

Published online: October 25, 2012

www.karger.com/kbr

Ohno/Ishimura/Naganuma et al.: Chronic Kidney Disease in Subject Without Notable Chronic Disease

Table 2: Univariate and multivariate logistic regression analysis of factors associated with chronic kidney disease (CKD) in all health checkup participants

\begin{tabular}{lcccccc}
\hline & \multicolumn{3}{c}{ Univariate } & \multicolumn{3}{c}{ Multivariate* } \\
\cline { 2 - 7 } & Odds ratio & $95 \%$ CI & $\mathrm{p}$ & Odds ratio & $95 \% \mathrm{CI}$ & $\mathrm{p}$ \\
\hline age (years) & & & & & & \\
$\quad 40-49$ & 1.00 & & & 1.00 & & \\
$50-59$ & 2.85 & $2.56-3.16$ & $<0.0001$ & 2.92 & $2.63-3.25$ & $<0.0001$ \\
$60-74$ & 4.83 & $4.37-5.34$ & $<0.0001$ & 4.92 & $4.45-5.44$ & $<0.0001$ \\
male & 1.12 & $1.06-1.18$ & $<0.0001$ & 0.83 & $0.78-0.88$ & $<0.0001$ \\
hypertension & 1.23 & $1.16-1.30$ & $<0.0001$ & 1.01 & $0.95-1.07$ & 0.8300 \\
diabetes & 0.84 & $0.69-1.03$ & 0.0898 & 0.80 & $0.66-0.98$ & 0.0307 \\
dyslipidemia & 1.43 & $1.23-1.66$ & $<0.0001$ & 1.21 & $1.04-1.42$ & 0.0138 \\
obesity & 1.34 & $1.26-1.42$ & $<0.0001$ & 1.23 & $1.16-1.31$ & $<0.0001$ \\
hyperuricemia & 2.39 & $2.22-2.58$ & $<0.0001$ & 2.63 & $2.41-2.86$ & $<0.0001$ \\
history of CVD & 1.43 & $1.20-1.71$ & $<0.0001$ & 1.26 & $1.05-1.51$ & 0.0135 \\
\hline * The multivariate model included all the variables in the table. CI: Confidence interval, CVD: \\
cardiovascular disease
\end{tabular}

Table 3: Univariate and multivariate logistic regression analysis of factors associated with chronic kidney disease (CKD) in male health checkup participants

\begin{tabular}{lcccccc}
\hline & \multicolumn{3}{c}{ Univariate } & \multicolumn{3}{c}{ Multivariate* } \\
\cline { 2 - 7 } & Odds ratio & $95 \%$ CI & $\mathrm{p}$ & Odds ratio & $95 \% \mathrm{CI}$ & $\mathrm{p}$ \\
\hline age (years) & & & & 1.00 & & \\
$\quad 40-49$ & 1.00 & & & & \\
$50-59$ & 1.13 & $0.93-1.36$ & 0.2222 & 1.20 & $0.99-1.46$ & 0.0659 \\
$60-74$ & 4.64 & $3.96-5.45$ & $<0.0001$ & 5.25 & $4.46-6.19$ & $<0.0001$ \\
hypertension & 1.33 & $1.21-1.45$ & $<0.0001$ & 1.05 & $0.95-1.16$ & 0.326 \\
diabetes & 0.80 & $0.62-1.03$ & 0.0815 & 0.81 & $0.62-1.05$ & 0.1121 \\
dyslipidemia & 1.41 & $1.16-1.72$ & 0.0006 & 1.26 & $1.02-1.55$ & 0.0339 \\
obesity & 1.43 & $1.30-1.57$ & $<0.0001$ & 1.40 & $1.26-1.55$ & $<0.0001$ \\
hyperuricemia & 2.30 & $2.09-2.53$ & $<0.0001$ & 2.51 & $2.26-2.78$ & $<0.0001$ \\
history of CVD & 1.42 & $1.05-1.91$ & 0.0221 & 1.17 & $0.85-1.60$ & 0.3438 \\
\hline * The multivariate model included all the variables in the table. CI: Confidence interval, CVD: \\
cardiovascular disease
\end{tabular}

95\% CI: 3.96-5.45, p<0.0001); (2) hypertension (1.33, 1.21-1.45, $\mathrm{p}<0.0001)$; (3) dyslipidemia (1.41, 1.16-1.72, p=0.0006); (4) obesity (1.43, 1.30-1.57, $\mathrm{p}<0.0001)$; (5) hyperuricemia (2.30, 2.09-2.53, p<0.0001); and (6) a history of CVD (1.42, 1.05-1.91, p=0.0221) (Table 3). The univariate logistic regression analysis in females demonstrated that the following were significant factors associated with the presence of CKD: (1) age of 50-59 years (OR: $3.84,95 \%$ CI: 3.37-4.38, $\mathrm{p}<0.0001)$, age of 60-74 years (4.95, 4.36-5.62, $\mathrm{p}<0.0001)$; (2) hypertension $(1.15,1.07-1.24, \mathrm{p}=0.0003) ;(3)$ dyslipidemia $(1.36,1.09-1.71, \mathrm{p}=0.0079) ;(3)$ obesity (1.27, 1.18-1.37, p<0.0001); (5) hyperuricemia (3.92, 3.30-4.66, p<0.0001); and (6) a history of CVD $(1.43,1.15-1.78, \mathrm{p}=0.0015)$ (Table 4).

Multivariate logistic regression analysis in males demonstrated that the following factors were significantly associated with the presence of CKD: (1) age of 60-74 years (OR: 5.25, 95\% CI: 4.46-6.19, p<0.0001); (2) dyslipidemia (1.26, 1.02-1.55, p=0.0339); (3) obesity $(1.40,1.26-1.55, \mathrm{p}<0.0001)$; and (4) hyperuricemia $(2.51,2.26-2.78, \mathrm{p}<0.0001)$ (Table 3). Multivariate logistic regression analysis in females demonstrated that the following factors 


\section{Kidney \\ Blood Pressure Research}

Kidney Blood Press Res 2012;36:139-148

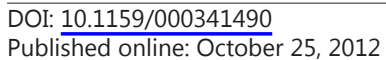

C 2012 S. Karger AG, Base

www.karger.com/kbr

Ohno/Ishimura/Naganuma et al.: Chronic Kidney Disease in Subject Without Notable Chronic Disease

Table 4: Univariate and multivariate logistic regression analysis of factors associated with chronic kidney disease (CKD) in female health checkup participants

\begin{tabular}{lcccccc}
\hline & \multicolumn{3}{c}{ Univariate } & \multicolumn{3}{c}{ Multivariate* } \\
\cline { 2 - 7 } & Odds ratio & $95 \% \mathrm{CI}$ & $\mathrm{p}$ & Odds ratio & $95 \% \mathrm{CI}$ & $\mathrm{p}$ \\
\hline age (years) & & & & & & \\
$40-49$ & 1.00 & & & 1.00 & & \\
$50-59$ & 3.84 & $3.37-4.38$ & $<0.0001$ & 3.80 & $3.33-4.32$ & $<0.0001$ \\
$\quad 60-74$ & 4.95 & $4.36-5.62$ & $<0.0001$ & 4.81 & $4.23-5.46$ & $<0.0001$ \\
hypertension & 1.15 & $1.07-1.24$ & 0.0003 & 0.98 & $0.91-1.06$ & 0.6111 \\
diabetes & 0.83 & $0.61-1.15$ & 0.2655 & 0.76 & $0.55-1.05$ & 0.0954 \\
dyslipidemia & 1.36 & $1.09-1.71$ & 0.0079 & 1.16 & $0.92-1.46$ & 0.2228 \\
obesity & 1.27 & $1.18-1.37$ & $<0.0001$ & 1.17 & $1.09-1.26$ & $<0.0001$ \\
hyperuricemia & 3.92 & $3.30-4.66$ & $<0.0001$ & 3.46 & $2.90-4.12$ & $<0.0001$ \\
history of CVD & 1.43 & $1.15-1.78$ & 0.0015 & 1.29 & $1.03-1.62$ & 0.0264 \\
\hline
\end{tabular}

* The multivariate model included all the variables in the table. CI: Confidence interval, CVD: cardiovascular disease

were significantly associated with the presence of CKD: (1) age of 50-59 years (OR: 3.80, 95\% CI: 3.33-4.32,p<0.0001), age of 60-74 years (4.81, 4.23-5.46, $\mathrm{p}<0.0001)$; (2) obesity $(1.17,1.09-1.26, \mathrm{p}<0.0001)$; (3) hyperuricemia $(3.46,2.90-4.12, \mathrm{p}<0.0001)$; and (4) a history of CVD (1.29,1.03-1.62, p=0.0264) (Table 4).

\section{Discussion}

In the present study, we examined the prevalence of CKD in a relatively large population $(n=39,211)$ of Osaka city. Although all of the study subjects underwent annual health checkups, it is notable that none of the participants visited local medical doctors or hospitals for the treatment of chronic diseases, i.e., hypertension, diabetes, liver diseases, or heart diseases, according to the self-administered questionnaire. Among these participants, we found that the prevalence of CKD was $20.5 \%$. We also found that significant factors associated with CKD were factors related to metabolic abnormalities, i.e., dyslipidemia, hyperuricemia, and obesity, even though subjects were unaware of these abnormalities, in addition to wellknown associated factors of older age and a history of CVD.

The prevalence of CKD in a community-based population has recently been reported as ranging from $8.3 \%$ to $19.2 \%[1,2,6-9,18-20]$. The prevalence of CKD differs among these studies, due to differences in the population, the number of people examined, age, and race. The main characteristic of the subjects in the present study is that the population number is relatively larger in the urban area of Osaka city. The number of subjects in the present study is far greater than previous studies that examined thousands of subjects [6-9, 19, $20]$. The prevalence of CKD in the present study (20.5\%) is slightly higher, compared with these previous studies. As has been well-established [1, 2, 6-9, 18-20], we observed that the prevalence of CKD increased with age (Figure 2). The higher prevalence of CKD in the present study may be due to the fact that subjects between 40 and 74 years of age were examined, thus excluding younger subjects, below 40 years of age.

Although hypertension was a factor associated significantly with the prevalence of CKD (OR: $1.23,95 \%$ CI: 1.16-1.30, p<0.0001) in univariate analysis in the present study, it was not a significant factor in multivariate analysis $(1.01,0.95-1.07, \mathrm{p}=0.8300)$. Significant associations of hypertension with CKD have been reported by others $[1,6-8,18,20]$, in contrast with the results of our multivariate analysis. These studies by others included subjects with evident hypertension among their study populations $[1,6-8,18,20]$. However, in our study, we 


\section{Kidney Blood Pressure Research}

Kidney Blood Press Res 2012;36:139-148

\begin{tabular}{l|l}
\hline DOI: $10.1159 / 000341490$ & (c) 2012 S. Karger AG, Basel
\end{tabular}

Published online: October 25, 2012

www.karger.com $/ \mathrm{kbr}$

Ono/Ishimura/Naganuma et al.: Chronic Kidney Disease in Subject Without Notable Chronic Disease

examined subjects without known hypertension or treatment for hypertension. The number of participants with hypertension in the present study was 8,995 out of the total number of participants of 39,211 (22.8\%), which was somewhat small. The blood pressure of the hypertensive subjects was $150 \pm 13$ / $87 \pm 10 \mathrm{mmHg}$, which was not particularly high, as they were not being treated with any anti-hypertensive medications. These may contribute to the non-significant association between hypertension and CKD in our multivariate analysis in the present study, although the definite reasons are not known.

Our study showed that obesity and dyslipidemia were significantly associated with the presence of CKD. Obesity was significantly associated with CKD in all participants, as well as in males and females. Obesity was previously reported to be significantly associated with the prevalence of CKD $[1,6,7,19]$. The results of our study are consistent with these previous studies. It has not been firmly established whether hyperlipidemia/dyslipidemia is associated with CKD. Kim et al. reported that hyperlipidemia was a significant factor associated with CKD [8]. Wang et al. reported that hypertriglyceridemia was a significant factor associated with CKD [20]; although it was not confirmed by others [6, 7]. Ninomiya et al. reported that increases in the components of metabolic syndrome, including hypertriglyceridemia, low HDL-cholesterol and abdominal obesity, were significantly associated with the development of CKD within 5 years [19]. Our study showed that dyslipidemia and obesity were independently, significantly associated with the presence of CKD in subjects with no medication or treatment.

Although many studies have analyzed several factors associated with CKD, a few studies have shown that hyperuricemia is associated with CKD [7, 8, 21]. In the present study, hyperuricemia was a significant factor associated with CKD in all participants, as well as in males and females, which was consistent with the previous studies [7, 8, 21]. Since uric acid is excreted in urine, decreased GFR in CKD patients would lead to elevated serum uric acid, resulting in the significant association of uric acid with the prevalence of CKD. However, Iseki et al. reported that hyperuricemia was an independent significant predictor of ESRD in women after adjustment for several confounders, based upon 25,228 women; whereas, in 22,949 men, hyperuricemia was a significant predictor of ESRD in a univariate Cox analysis [21]. Considering their results and our own, hyperuricemia may be considered a risk factor for the presence of CKD in our study population.

In the present study, diabetes was significantly and inversely associated with the presence of CKD. In previous studies, however, the presence of diabetes was reported to be significantly and positively associated with the presence of CKD $[1,6,7,18,20]$. It should be noted that these previous studies included subjects with confirmed diagnoses of diabetes in their cohort. In the present study, subjects who regularly visited local medical doctors or hospitals were not included, suggesting that we likely included subjects with early stage or undiagnosed diabetes. Hyperfiltration (increased GFR) is often seen in the early stage of diabetes [22]. In the study of the general Japanese population by Imai et al. [2], the diabetic population, based upon hemoglobin $\mathrm{A} 1 \mathrm{C} \geq 6.0$, exhibited significantly increased GFR. The increased GFR in the early stage of diabetes in the annual health checkup subjects may be associated with the decreased prevalence of CKD in the present study, as assessed by GFR and proteinuria.

Concerning the differences in CKD prevalence between males and females, conflicting results have been reported $[6-9,19,20]$. We found that male gender was positively associated with CKD in the univariate analysis (OR: 1.12, 95\% CI: 1.06-1.18, p<0.0001), whereas male gender was inversely associated with CKD in the multivariate analysis $(0.83,0.78-0.88$, $\mathrm{p}<0.0001)$. In the logistic model, in which male gender was an explanatory variable of interest and the other variables were sequentially entered into the model as confounders, male gender was found to be significantly and positively associated with CKD only after adjustment for hyperuricemia (OR: 1.15, 95\% CI: 1.09-1.22, p<0.0001); although male gender was found to be inversely associated with CKD after adjustment for each of the other factors of age, hypertension, diabetes, dyslipidemia, obesity, and history of CVD (OR: 0.93, 95\% CI: 0.880.98, p<0.005; OR: 0.92, 95\% CI: 0.87-0.97, p<0.005; OR: 0.89, 95\% CI: 0.85-0.94, p<0.0001; 


\section{Kidney \\ Blood Pressure Research}

Kidney Blood Press Res 2012;36:139-148

\begin{tabular}{l|l}
\hline DOI: $10.1159 / 000341490$ & (c) 2012 S. Karger AG, Basel
\end{tabular}

Published online: October 25, 2012

www.karger.com/kbr

Ohno/Ishimura/Naganuma et al.: Chronic Kidney Disease in Subject Without Notable Chronic Disease

OR: 0.91, 95\% CI: 0.86-0.95, p<0.0005; OR: 0.92, 95\% CI: 0.87-0.97, p<0.005; OR: 0.90, 95\% CI: $0.85-0.95, p<0.0001$, respectively). In the present study, hyperuricemia was defined as serum uric acid $\geq 7.0 \mathrm{mg} / \mathrm{dl}$ in both genders, according to the guidelines of the Japanese Society of Gout and Nucleic Acid Metabolism [14]. In general, uric acid levels are higher in males $[21,23]$. Indeed, hyperuricemia was observed in $23.9 \%$ of males compared with $1.9 \%$ of females in the present study. Thus the higher uric acid levels in males may explain the apparent positive relationship between male gender and CKD in the univariate analysis.

Through the present analyses of a large number of urban residents $(n=39,211)$ who were unaware of CKD, as much as $20.5 \%$ of the subjects actually had CKD. Further, even though they were unaware of the presence of metabolic abnormalities of dyslipidemia, hyperuricemia, and obesity, these factors were significantly associated with the presence of CKD. It is considered that, as a strategy for CKD prevention and inhibition of CKD progression, social recognition of CKD should be emphasized. Further, CKD-associated factors of dyslipidemia, hyperuricemia, and obesity should be measured in the annual health checkup, and these factors should be treated as early as possible, to prevent the occurrence and progression of CKD.

There are some limitations in the present study. First, in our study, participants were not selected randomly from the urban population, resulting in a sample comprised of a greater number of females than males. Thus, we analyzed factors associated with CKD separately in males and females, in the present study. Second, our study did not analyze the factors associated with proteinuria. Actually, number of subjects with proteinuria of $(+)$ $(\mathrm{n}=542)$ and $(++)(\mathrm{n}=210)$ was too small to obtain an enough statistical power to analyze factors associated with proteinuria. Third, the cross-sectional design of the present study did not reveal a causal relationship between the presence of CKD and the factors associated with CKD. However, we showed that several factors, including metabolic abnormalities, were significantly associated with the presence of CKD.

\section{Conclusion}

We examined the prevalence of CKD and analyzed factors associated with CKD in a large number of urban subjects undergoing an annual health checkup, who did not otherwise regularly visit their local medical doctors or hospitals for treatment of chronic disease. In this population aged 40-74 years without known notable diseases, the prevalence of CKD was as high as $20.5 \%$. Several metabolic abnormalities, i.e., dyslipidemia and hyperuricemia, were significantly associated with the prevalence of CKD after adjustment for the well-known risk factors of older age, the presence of hypertension and a history of CVD. Further studies are required to determine whether these metabolic factors are predictors of the development of CKD and the mechanisms by which these metabolic factors are associated with CKD.

\section{Conflict of Interests}

The authors declare that they have no conflicts.

\section{Acknowledgements}

This study was conducted in cooperation with the Public Health Division, Public Health Bureau, Osaka city, Japan 


\section{Kidney \\ Blood Pressure Research}

Kidney Blood Press Res 2012;36:139-148

\begin{tabular}{l|l}
\hline DOI: $10.1159 / 000341490$ & (c) 2012 S. Karger AG, Basel
\end{tabular}

Published online: October 25, 2012

www.karger.com/kbr

\section{References}

1 Coresh J, Selvin E, Stevens LA, Manzi J, Kusek JW, Eggers P, Van Lente F, Levey AS: Prevalence of chronic kidney disease in the united states. JAMA 2007;298:2038-2047.

2 Imai E, Horio M, Watanabe T, Iseki K, Yamagata K, Hara S, Ura N, Kiyohara Y, Moriyama T, Ando Y, Fujimoto S, Konta T, Yokoyama H, Makino H, Hishida A, Matsuo S: Prevalence of chronic kidney disease in the japanese general population. Clin Exp Nephrol 2009;13:621-630.

-3 Keith DS, Nichols GA, Gullion CM, Brown JB, Smith DH: Longitudinal follow-up and outcomes among a population with chronic kidney disease in a large managed care organization. Arch Intern Med 2004;164:659-663.

-4 Sarnak MJ, Levey AS, Schoolwerth AC, Coresh J, Culleton B, Hamm LL, McCullough PA, Kasiske BL, Kelepouris E, Klag MJ, Parfrey P, Pfeffer M, Raij L, Spinosa DJ, Wilson PW: Kidney disease as a risk factor for development of cardiovascular disease: A statement from the american heart association councils on kidney in cardiovascular disease, high blood pressure research, clinical cardiology, and epidemiology and prevention. Circulation 2003;108:2154-2169.

5 Culleton BF, Hemmelgarn BR: Is chronic kidney disease a cardiovascular disease risk factor? Semin Dial 2003;16:95-100.

6 Kim S, Lim CS, Han DC, Kim GS, Chin HJ, Kim SJ, Cho WY, Kim YH, Kim YS: The prevalence of chronic kidney disease (ckd) and the associated factors to ckd in urban korea: A population-based cross-sectional epidemiologic study. J Korean Med Sci 2009;24 Suppl:S11-21.

7 Chen N, Wang W, Huang Y, Shen P, Pei D, Yu H, Shi H, Zhang Q, Xu J, Lv Y, Fan Q: Community-based study on ckd subjects and the associated risk factors. Nephrol Dial Transplant 2009;24:2117-2123.

8 Takamatsu N, Abe H, Tominaga T, Nakahara K, Ito Y, Okumoto Y, Kim J, Kitakaze M, Doi T: Risk factors for chronic kidney disease in japan: A community-based study. BMC Nephrol 2009;10:34.

$>9$ Nagata M, Ninomiya T, Doi Y, Yonemoto K, Kubo M, Hata J, Tsuruya K, Iida M, Kiyohara Y: Trends in the prevalence of chronic kidney disease and its risk factors in a general japanese population: The hisayama study. Nephrol Dial Transplant 2010;25:2557-2564.

10 Ogihara T, Kikuchi K, Matsuoka H, Fujita T, Higaki J, Horiuchi M, Imai Y, Imaizumi T, Ito S, Iwao H, Kario K, Kawano Y, Kim-Mitsuyama S, Kimura G, Matsubara H, Matsuura H, Naruse M, Saito I, Shimada K, Shimamoto K, Suzuki H, Takishita S, Tanahashi N, Tsuchihashi T, Uchiyama M, Ueda S, Ueshima H, Umemura S, Ishimitsu T, Rakugi H: The japanese society of hypertension guidelines for the management of hypertension (jsh 2009). Hypertens Res 2009;32:3-107.

-11 Seino Y, Nanjo K, Tajima N, Kadowaki T, Kashiwagi A, Araki E, Ito C, Inagaki N, Iwamoto Y, Kasuga M, Hanafusa T, Haneda M, Ueki K: Report of the committee on the classification and diagnostic criteria of diabetes mellitus. Diabetol Int 2010;1:2-20.

-12 Shimano H, Arai H, Harada-Shiba M, Ueshima H, Ohta T, Yamashita S, Gotoda T, Kiyohara Y, Hayashi T, Kobayashi J, Shimamoto K, Bujo H, Ishibashi S, Shirai K, Oikawa S, Saito Y, Yamada N: Proposed guidelines for hypertriglyceridemia in japan with non-hdl cholesterol as the second target. J Atheroscler Thromb 2008;15:116-121.

13 New criteria for 'obesity disease' in japan. Circ J 2002;66:987-992.

14 Digest of guideline for the management of hyperuricemia and gout 2 nd edition. The guideline revising committee of japanese society of gout and nucleic acid metabolism. Gout Nucleic Acid Metabolism 2010;34:109-144.

15 Report of the expert committee on the diagnosis and classification of diabetes mellitus. Diabetes Care 1997;20:1183-1197.

-16 Matsuo S, Imai E, Horio M, Yasuda Y, Tomita K, Nitta K, Yamagata K, Tomino Y, Yokoyama H, Hishida A: Revised equations for estimated gfr from serum creatinine in japan. Am J Kidney Dis 2009;53:982-992.

17 Levey AS, Eckardt KU, Tsukamoto Y, Levin A, Coresh J, Rossert J, De Zeeuw D, Hostetter TH, Lameire N, Eknoyan G: Definition and classification of chronic kidney disease: A position statement from kidney disease: Improving global outcomes (kdigo). Kidney Int 2005;67:2089-2100.

18 Yamagata K, Ishida K, Sairenchi T, Takahashi H, Ohba S, Shiigai T, Narita M, Koyama A: Risk factors for chronic kidney disease in a community-based population: A 10-year follow-up study. Kidney Int 2007;71:159-166. 


\section{Kidney

Ohno/Ishimura/Naganuma et al.: Chronic Kidney Disease in Subject Without Notable Chronic Disease

19 Ninomiya T, Kiyohara Y, Kubo M, Yonemoto K, Tanizaki Y, Doi Y, Hirakata H, Iida M: Metabolic syndrome and ckd in a general japanese population: The hisayama study. Am J Kidney Dis 2006;48:383-391.

20 Wang F, Ye P, Luo L, Xiao W, Wu H: Association of risk factors for cardiovascular disease and glomerular filtration rate: A community-based study of 4,925 adults in beijing. Nephrol Dial Transplant 2010;25:39243931.

-21 Iseki K, Ikemiya Y, Inoue T, Iseki C, Kinjo K, Takishita S: Significance of hyperuricemia as a risk factor for developing esrd in a screened cohort. Am J Kidney Dis 2004;44:642-650.

-22 Jin Y, Moriya T, Tanaka K, Matsubara M, Fujita Y: Glomerular hyperfiltration in non-proteinuric and nonhypertensive japanese type 2 diabetic patients. Diabetes Res Clin Pract 2006;71:264-271.

23 Messerli FH, Frohlich ED, Dreslinski GR, Suarez DH, Aristimuno GG: Serum uric acid in essential hypertension: An indicator of renal vascular involvement. Ann Intern Med 1980;93:817-821. 